\title{
Índice general de los números 23 a 40
}

Academia Costarricense de la Lengua, «Personas que han integrado la ACADEMIA CostaRricense DE La Lengua (con indicación de sus períodos)», Letras 40 (2006) 255-258.

Acuña, María Eugenia, «La imagen de la mujer en la literatura costarricense de principios de siglo», Letras 23-24 (1990) 149-159.

Agüero Chaves, Arturo, «Cronología de la Academia Costarricense de la Lengua», Letras 40 (2006) 213-254.

Aguilar Gutiérrez, Alma Rosa, «Sur l'universe fantastique de Julio Cortázar: analyse semantique de la referenciation dans Pasajes», Letras 31 (1999) 25-45.

Aguilar Gutiérrez, Alma Rosa, «Crear vínculos, mirar con el corazón», Letras 32 (2000) 171-180.

Aguilar Gutiérrez, Alma Rosa, «Heroínas naturalistas de la modernidad: Germinal de Emile Zola», Letras 37 (2005) 95-113.

Aguilar Gutiérrez, Alma Rosa, «Juegos referenciales y configuraciones espaciales el universo fantástico en "Ahí pero dónde, cómo" de Julio Cortázar», Letras 38 (2005) 49-73.

Alvarado, María Luisa, «El poema "Pisada humana" de Vicente Aleixandre», Letras 23-24 (1990) 201-211.

Álvarez Martínez, Luis Gustavo, «Wrath in Diane Wakoski's Poetry», Letras 36 (2004) 205-213. 
Álvarez Martínez, Luis Gustavo, «An Annotated Bibliography on the Rabbit Novels by John Updike», Letras 39 (2006) 161-182.

Araya, Seidy, «El examen ético de la historia en Cenizas de Izalco de C. Alegría y D. J. Flakoll», Letras 25-26 (1991) 61-82.

Araya, Seidy, «La mujer y la agresión en "Quince barrotes de izquierda a derecha" de Rosario Aguilar», Letras 29-30 (1993) 113-126.

Araya, Seidy, «El diálogo intertextual en Mayapán», Letras 32 (2000) 65-90.

Araya, Seidy, «Frida Calho y Eunice Odio. El surrealismo latinoamericano, imágenes pictóricas y verbales», Letras 35 (2003) 103-115.

Araya, Seidy, «El advenimiento de una nueva realidad en Mujeres, sombras y coloquios de uno, de Eduardo Vargas Ugalde», Letras 38 (2005) 91-100.

Arrieta Vargas, Vilma, «Presencia satánica en el Río Danubio: anagramas en "Lejana", de Julio Cortázar», Letras 32 (2000) 45-64.

Arrieta Vargas, Vilma, «El eco de otra Alina, Intertextualidades en "Lejana” de Julio Cortázar», Letras 38 (2005) 75-89.

Azofeifa, Isaac Felipe, «Notas para una interpretación provisional de la poesía en Latinoamérica», Letras 23-24 (1990) 187-199.

Azofeifa, Isaac Felipe, «La posición actual de los estudios literarios y lingüísticos y nuestra enseñanza del castellano», Letras 29-30 (1993) 241260.

Baltodano Román, Gabriel, «Los hilos de lo desconocido: Luzbel, de Gonzalo Arias Páez», Letras 38 (2005) 101-121.

Baltodano Román, Gabriel, «Versos y reversos: a propósito de la voluntad, la lectura y El Quijote», Letras 39 (2006) 27-46. 
Barboza Núñez, Esteban, «The Uncanny in the Themesof Evil, Transgression, and the Double in Nathaniel Hawthorne's "Rappaccini's Daughter" », Letras 40 (2006) 33-47.

Barzuna Pérez, Guillermo, «Del contexto y los desplazamientos en la nueva canción latinoamericana», Letras 27-28 (1992) 7-23.

Barzuna Pérez, Guillermo, «Graffiti: la voz ante el silencio», Letras 37 (2005) 129-138.

Benavides Segura, Bianchinetta, «El tratamiento completo: alternativa para la traducción del verso inserto en prosa no literaria», Letras 39 (2006) 183-203.

Benavides Segura, Bianchinetta, «La traducción de verso inserto en prosa: dos casos», Letras 40 (2006) 93-115.

Blanco Benavides, Carlos, «La sanción a un gamonal: "La propia", de Magón», Letras 35 (2003) 133-151.

Bolaños, Luis, «Un poeta entre la vocación y el deber: Entrevista con Carlos Francisco Monge», Letras 23-24 (1990) 213-230.

Boza Araya, Virginia, «L'interculturel dans l'espacie francophone», Letras 37 (2005) 167-185.

Boza Araya, Virginia, "L'universe fantastique de Jean Ray», Letras 38 (2005) 123-151.

Budd, Ruth, «Basura y tesoros en el relleno sanitario de Río Azul: una nueva mirada a la "Suiza de América Central"», Letras 31 (1999) 121-130.

Calderón, Juan Roberto, «Entre dos sellos: el esoterismo islámico de la "Azora en los infieles"», Letras 37 (2005) 115-127.

Calderón, Juan Roberto, «En el vientre de la redoma: los genios en Las mil y una noches», Letras 38 (2005) 153-165. 
Calderón, Juan Roberto, «Breve acercamiento a la literatura árabe», Letras 31 (1999) 131-152.

Calderón, Mínor, «Única mirando al mar: entre la transgresión y la norma», Letras 35 (2003) 173-184.

Calderón, Sonia, «Dificultad de los verbos fraseológicos en inglés para hispanohablantes», Letras 39 (2006) 205-222.

Cantillano, Odilie, «Aspectos folklóricos en Cuentos de mi tía Panchita», Letras 33 (2001) 33-100.

Cantillano, Odilie, «Los cuentos de tío Conejo», Letras 34 (2002) 5-42.

Carcaud, Monique, «Sociocrítica y fenómenos de transtextualidad», Letras 33 (2001) 101-114.

Carrasco, Candide, «Voces gay en la narrativa costarricense», Letras 35 (2003) 81-101.

Castro García, Damaris, «Spanish/English Bilingualism and Finiteness Acquisition», Letras 40 (2006) 141-173.

Castro Villalobos, Marielos, «Lectura sociohistórica y simbólica de El luto humano de José Revueltas», Letras 27-28 (1992) 69-86.

Chacón Gutiérrez, Albino, «Lainscripción delas mediaciones institucionales en Lázaro de Betania, de Roberto Brenes Mesén y "Caballo de trote", de Quince Duncan», Letras 35 (2003) 197-209.

Chacón Gutiérrez, Albino, «La literatura histórica en Costa Rica hoy», Letras 39 (2006) 227-235.

Chacón Araya, Xinia, "A Materials Design Model», Letras 31 (1999) 91-103. 
Chacón Araya, Xinia, «Student's First Approach to Reading Comprehension: Pre-Reading Strategies», Letras 32 (2000) 121-136.

Chacón Araya, Xinia, «The English Reading Comprehension Class: InReading and Post-Reading strategies», Letras 34 (2002) 43-58.

Chacón Araya, Xinia, «Programa de inmersión del Español como segunda lengua para profesionales», Letras 36 (2004) 161-174.

Chavarría Fonseca, Rosa Isabel, «Stereotypes of Latin American Women Found in the Textbook of Spanish-as-a-Foreign-Language», Letras 27-28 (1992) 133-162.

Chavarría Fonseca, Rosa Isabel, «Improving the Curriculum Through a Unified Content-Area-Based Approach», Letras 29-30 (1993) 173-200.

Chavarría Fonseca, Rosa Isabel, «English Locative Prepositions in, on, at and Spanish Locative Prepositions en and sobre», Letras 34 (2002) 59-72.

Chaverri, Amalia, «Cruz de olvido: historia, ficción y catarsis», Letras 35 (2003) 37-54.

Chaves Alfaro, Iris, «"Las babas del diablo" de Julio Cortázar: la rebelión del relato», Letras 27-28 (1992) 49-66.

Chaves Alfaro, Iris, «Desconciertos en un jardín tropical de Magda Zavala: crónica de la posmodernidad», Letras 35 (2003) 153-172.

Chaves Solano, Magaly, «Consideraciones metodológicas para la traducción directa Consideraciones metodológicas para la traducción directa», Letras 36 (2004) 101-117.

Cortés, María Lourdes, «El espejo, el andrógino y la madre», Lctrurs is (2003) 55-64. 
Dianda, Ana María, «Intertextualidad y simbolismo: su importancia en la traducción y la recreación del texto literario», Letras 32 (2000) 91-106.

Dormond, Cinthia, «George Sand precursora del movimiento feminista», Letras 23-24 (1990) 137-147.

Durán Luzio, Juan, «"Crónicas marcianas": de la conquista de América a la conquista de Marte», Letras 25-26 (1991) 83-106.

Durán Luzio, Juan, «Borges y los libros», Letras 31 (1999) 153-156.

Eliason, Walter, «La adquisición de una segunda lengua como agente de cambio en la enseñanza», Letras 29-30 (1993) 153-171.

Enríquez, María, «Miradas convergentes sobre la cuidad en Los Peor de Fernando Contreras», Letras 37 (2005) 53-64.

Gaínza, Gastón, «La lectura de la otredad», Letras 29-30 (1993) 7-20.

Gaínza, Gastón, «Pespuntes semióticos», Letras 31 (1999) 47-68.

Gaínza, Gastón, «El libro y la provocación del sentido», Letras 39(2006) 11-25.

Gaínza, Gastón, «La traducción: interacción de semiosferas», Letras 39 (2006) 237-244.

Gamboa Goldemberg, Jaime, «Borges y Dios en el jardín del soneto», Letras 25-26 (1991) 25-40.

Gamboa Goldemberg, Jaime, «Lectura y consagración en El hondero entusiasta de Pablo Neruda», Letras 33 (2001) 143-150.

Gapper, Sherry, «Anexo a "La teoría y el arte de la traducción" de Peter Newmark: Bibliografía esencial sobre traducción», Letras 23-24 (1990) 59-66. 
Gapper, Sherry, «La traducción como campo de estudio: tendencias y posibilidades actuales», Letras 25-26 (1991) 121-138.

Gapper, Sherry, «La firma de quien traduce», Letras 36 (2004) 81-99.

Gólcher, Ingrid, «Educación del traductor como pensador crítico», Letras 36 (2004) 65-80.

Gómez, Gilberto, «El proyecto nacional colombiano y la defensa de la aristocracia en Pax y El alférez real», Letras 37 (2005) 65-77.

González Duarte, Delma, «Signos de violencia en La colina de Daniel Gallegos», Letras 27-28 (1992) 25-47.

Grivel, Charles, «Buñuel ou l'insoutenable filmique», Letras 29-30 (1993) 127-152.

Guzmán Arguedas, María de la Luz, «El análisis retórico de la publicidad», Letras 23-24 (1990) 127-136.

Guzmán Arguedas, María de la Luz, «Juventud y vejez de Lope de Vega en su poesía», Letras 25-26 (1991) 5-24.

Haffner, Françoise, «Valéry mythoclaste», Letras 34 (2002) 87-104.

Hernández Villalobos, Jorge, «The Socio-Cultural Content of Textbooks and the Teaching of Culture in Foreign Language Programs», Letras 23-24 (1990) 83-104.

Herzfeld, Anita, «La autoimagen de los hablantes del criollo limonense», Letras 25-26 (1991) 139-158.

Jiménez Arias, Ivannia, «Writing is not so tough!», Letras 27-28 (1992) 163-191. 
Jiménez Arias, Ivannia, «Treating Students' Errors in Oral Production», Letras 36 (2004) 175-188.

Kühlmann Berenzon, Helga, «La formación del traductor en el lugar del trabajo», Letras 36 (2004) 119-139.

Lavou Zoungo, Victorien, «Indigenismo y marginación de los negros en América Latina», Letras 33 (2001) 129-142.

Limami, Abdellatif, «La cuidad marroquí en Los nombres del aire de Alberto Ruy Sánchez y Aguafuertes españoles de Roberto Arlt», Letras 34 (2002) 105-120.

Maristany, José María, «El vuelo del tigre: una contestación doblemente marginal», Letras 29-30 (1993) 55-73.

Martínez, Ana Teresa, «Usos innovadores de estar en la comunidad bilingüe de El Paso Texas», Letras 27-28 (1992) 193-215.

Matarrita, Estebana, «La relevancia de la excusa en El negro Francisco», Letras 34 (2002) 155-168.

Méndez, Carlos Adolfo, «El gran Gatsby de F. S. Fitzgerald: un acercamiento a su intertextualidad», Letras 27-28 (1992) 87-104.

Monge, Carlos Franscisco, «El estante vacío (Reflexiones sobre la poesía contemporánea)», Letras 33 (2001) 5-20.

Monge, Carlos Franscisco, «Andanzas españolas de la poesía costarricense», Letras 40 (2006) 75-91.

Montanaro, Óscar, «Huellas de ceniza: primera novela policial de la literatura costarricense», Letras 35 (2003) 211-225.

Murillo Miranda, José Manuel, «La nueva morfología y sintaxis», Letras 34 (2002) 73-86.

268 
Newmark, Peter, «La teoría y el arte de la traducción», Letras 23-24 (1990) 27-58.

Novo Díaz, Margarita, «La evaluación de las actividades de interpretación», Letras 36 (2004) 9-25.

Núñez Quesada, María Gabriela, «Proyecto Francés y Educación: veinte años de esfuerzos por el mejoramiento de la enseñanza del francés en Costa Rica», Letras 40 (2006) 175-208.

Ovares Ramírez, Flora, «Espacios de tránsito en los cuentos fantásticos de Julio Cortázar», Letras 31 (1999) 5-24.

Ovares Ramírez, Flora, «Tenía por sobrenombre Quesada», Letras 35 (2003) 7-10.

Ovares Ramírez, Flora, «La crítica en las revistas literarias en Costa Rica», Letras 39 (2006) 245-249.

Pérez Miguel, Rafael, «La huida imposible: "Rota la ternura", Marín Cañas», Letras 32 (2000) 5-18.

Pérez Miguel, Rafael, "Así nacimos (épica y antiépica en la literatura costarricense)», Letras 35 (2003) 227-235.

Pineda Rodríguez, Allan, «La traducción de criptogramas y poemas en $E l$ Código Da Vinci», Letras 40 (2006) 117-140.

Pizarro Chacón, Ginneth, «Etnoornitología guatusa», Letras 37 (2005) 139-165.

Quesada Soto, Alvaro, «La narrativa costarricense del último tercio de siglo», Letras 32 (2000) 17-44.

Quesada Pacheco, Jorge, «Code switching between Inglés y Español», Letras 23-24 (1990) 67-82. 
Quesada, Juan Diego, «Notas sobre epistemología del lenguaje», Letras 2324 (1990) 5-25.

Quesada, Miguel Ángel, «El participio con complemento pronominal en el español de Costa Rica», Letras 37 (2005) 5-29.

Quesada Monge, Rodrigo, «El problema del antiimperialismo en Máximo Soto Hall», Letras 25-26 (1991) 41-59.

Ramírez, Grethel, «Apuntes acerca de la ironía y otras variantes humorísticas», Letras 40 (2006) 9-31.

Ramírez Caro, Jorge, «Lecturas intertextual e interdiscursiva en Sociocrítica», Letras 32 (2000) 137-162.

Ramírez Caro, Jorge, «Un laberinto para jugar a la soledad: "La casa de Asterión"», Letras 38 (2005) 27-48.

Ramírez Caro, Jorge, «El Lazarillo de Tormes: texto carnavalesco. Contra las lecturas satíricas y erasmistas», Letras 39 (2006) 47-71.

Ramírez Caro, Jorge, «Juego a escondidas entre Dios y el ser humano en la poesía de Antonio Machado», Letras 40 (2006) 49-73.

Retana Calderón, Róger, «Dixiéme Lettre: Sur le commerce, Lettres Philosophiques, Voltaire. Approache discursive», Letras 32 (2000) 163-170.

Robb, Anthony, «Uvieta: aproximaciones literarias», Letras 35 (2003) 25-35.

Robb, Anthony, «El ser sexual en la poesía de Eunice Odio», Letras 39 (2006) 107-140.

Rodríguez, Cristián, «Traducciones comerciales y traducciones literarias», Letras 36 (2004) 219-224. 
Rojas Chaves, Carmen, «Actitudes hacia la enseñanza de las lenguas indígenas», Letras 39 (2006) 267-271.

Rojas González, Margarita, «Nación y familia: En una silla de ruedas de Carmen Lyra», Letras 23-24 (1990) 161-185.

Rojas González, Margarita, «Espacios de tránsito en los cuentos fantásticos de Julio Cortázar», Letras 31 (1999) 5-24.

Rojas González, Margarita, «Escritura e identidad en el cuento costarricense contemporáneo», Letras 35 (2003) 185-195.

Rojas González, Margarita, «El libro maligno: Aura e Inez», Letras 38 (2005) 9-26.

Rojas González, Margarita, «Los estudios teóricos de la literatura y la necesidad de la interpretación», Letras 39 (2006) 251-265.

Rojas González, Manuel, «Música callada: literatura y arte musical en tres cuentos hispanoamericanos», Letras 37 (2005) 79-94.

Rojas Campos, Oscar, «Authenticity in Listening and Written Texts», Letras 25-26 (1991) 169-194.

Rojas Campos, Oscar, «Procedimiento para analizar libros de texto comunicativos en la enseñanza de una segunda lengua o una lengua extranjera», Letras 27-28 (1992) 105-131.

Rojas Campos, Oscar, «El portafolio y la evaluación del proceso en traducción», Letras 36 (2004) 27-64.

Ruiz, Blanca Estela, «"La Tremenda Corte": un caso de lingüisticidio», Letras 34 (2002) 169-184.

Saborío Pérez, Ileana, «An ESL/EFL Computer Assisted Language Instruction (CALIS) Lesson on Coherence Through Sentences When Writing Compositions in the Foreign Language Classroom», Letras 36 (2004) 141-159. 
Saborío Pérez, Ileana, «Introspección curricular de la enseñanza del Inglés desde primaria y secundaria y sus posibles repercusiones académicas», Letras 39 (2006) 273-278.

Salas Zamora, Edwin, «Génesis de la identidad costarricense en Asalto al paraíso», Letras 35 (2003) 117-131.

Sánchez, Cristián Marcelo, «Entre dos sellos: el esoterismo islámico de la "Azora en los infieles"», Letras 37 (2005) 115-127.

Sánchez, Cristián Marcelo, «En el vientre dela redoma: los genios en Las mil y una noches», Letras 38 (2005) 153-165.

Sánchez García, Manuel, «Algunos problemas eñ la traducción al español del soneto XX de William Shakespeare», Letras 27-28 (1992) 217-231.

Shmigalle, Günther, «Escándalos de París. Rubén Darío y Gyp frente al asunto Syventon», Letras 37 (2005) 31-51.

Singer, Deborah, «La construcción de la identidad nacional patriarcal en Misterio, de Manuel Argüello Mora», Letras 39 (2006) 87-105.

Sirias, Silvio, «El nuevo "boom": la novela hispanoamericana en los Estados Unidos», Letras 29-30 (1993) 39-53.

Soriano, Michelle, «Esfinges y panteras: diferencia e ideología. Hacia un análisis sociocrítico de la apuesta especular», Letras 33 (2001) 115-128.

Thornton, Sally, «Highlighting Ambiguities: the Fictionalization of a Woman's Life in Lorenza Reynafé o Quiroga, la barranca de la tragedia», Letras 33 (2001) 21-32.

Tomcsányi Major, Judit, «Armonía vocálica y construcción simbolizadora en el lenguaje», Letras 25-26 (1991) 235-256. 
Tomcsányi Major, Judit, «Periodicidad y ciclicidad en la adquisición de los medios de expresión temporal en el inglés como lengua extranjera», Letras 36 (2004) 189-203.

Torres-Pou, Joan, «La carnavalización del discurso naturalista en A fuego lento, de Emilio Bobadilla», Letras 39 (2006) 73-86.

Umaña, José Otilio, «Interpretación y traducción de América en el "Diario de Navegación" de Cristobal Colon», Letras 25-26 (1991) 107-119.

Umaña, José Otilio, «Peregrinaciones hacia lo grotesco: tres cuentos de García Márquez», Letras 29-30 (1993) 101-112.

Urra Salazar, Marcos, «Reflexiones teóricas acerca del cuento», Letras 2324 (1990) 105-126.

Valembois, Victor, «Cien años de soledad: realismo belga en lo maravilloso», Letras 31 (1999) 105-120.

Valembois, Victor, «Miguel Ángel Asturias y Bélgica: curiosas pistas reales e imaginarias», Letras 32 (2000) 107-120.

Valembois, Victor, «De Bartolomé de Las Casas al TLC, pasando por Multatuli», Letras 39 (2006) 141-159.

Valencia, Jhon, «Género, homofobia interiorizada y falocentrismo a través de La mujer oculta», Letras 35 (2003) 65-79.

Vega Carballo, Virginia, «Fonética y enseñanza del francés», Letras 25-26 (1991) 209-219.

Vidaurre, Carmen, «Acercamiento analítico a Perésfone de Homero Aridjis», Letras 33 (2001) 151-159.

Villaceque, Sol, «Ruptura y modernidad. La renovación de los estereotipos en la Argentina de los años 20: El juguete rabioso de Roberto Arlt», Letras 34 (2002) 121-154. 
Villalobos, Carlos, «La episteme dialógica: el camino teórico de Álvaro Quesada», Letras 35 (2003) 11-23.

Villalobos Rodríguez, Lelia, «A Comparison of the Psychological Processes in Top-Down and Bottom-Up Processing of Information in Schema Theory», Letras 25-26 (1991) 195-208.

Villalobos Rodríguez, Lelia, «Foreign Language in the Elementary School (FLES) A Curriculum Proposal for First Grades», Letras 29-30 (1993) 201-224.

Villalobos Gamboa, María Eugenia, «Las voces verbales del español», Letras 25-26 (1991) 221-234.

Villalobos Gamboa, María Eugenia, «Bribri: lengua con cláusulas relativas del núcleo interno», Letras 29-30 (1993) 225-239.

Wilson, Diana de Armas, «Cervantes y "La materia de America"», Letras 2930 (1993) 21-38.

Yglesias, María Pérez, «La ironía del chiste», Letras 34 (2002) 185-199. 


\section{Índice temático de los números 23 a 40}

\section{Documentos varios}

Academia Costarricense de la Lengua, «Personas que han integrado la ACADEmia Costarricense de la Lengua (con indicación de sus períodos)», Letras 40 (2006) 255-258.

Agüero Chaves, Arturo, «Cronología de la Academia Costarricense de la Lengua», Letras 40 (2006) 213-254.

Azof eifa, Isaac Felipe, «Laposición actual delosestudios literarios y lingüísticos y nuestra enseñanza del castellano», Letras 29-30 (1993) 241-260.

\section{Lingüística}

Boza Araya, Virginia, «L'interculturel dans l'espacie francophone», Letras 37 (2005) 167-185.

Herzfeld, Anita, «La autoimagen de los hablantes del criollo limonense», Letras 25-26 (1991) 139-158.

Martínez, Ana Teresa, «Usos innovadores de estar en la comunidad bilingüe de El Paso Texas», Letras 27-28 (1992) 193-215.

Murillo Miranda, José Manuel, «La nueva morfología y sintaxis», Letras 34 (2002) 73-86.

Pizarro Chacón, Ginneth, «Etnoornitología guatusa», Letras 37 (2005) 139-165. 
Quesada, Juan Diego, «Notas sobre epistemología del lenguaje», Letras 2324 (1990) 5-25.

Quesada, Miguel Ángel, «El participio con complemento pronominal en el español de Costa Rica», Letras 37 (2005) 5-29.

Rojas Chaves, Carmen, «Actitudes hacia la enseñanza de las lenguas indígenas», Letras 39 (2006) 267-271.

Ruiz, Blanca Estela, «"La Tremenda Corte": un caso de lingüisticidio», Letras 34 (2002) 169-184.

Tomcsányi Major, Judit, «Armonía vocálica y construcción simbolizadora en el lenguaje», Letras 25-26 (1991) 235-256.

Villalobos Gamboa, María Eugenia, «Las voces verbales del español», Letras 25-26 (1991) 221-234.

Villalobos Gamboa, María Eugenia, «Bribri: lengua con cláusulas relativas del núcleo interno», Letras 29-30 (1993) 225-239.

\section{Lingüística aplicada a la enseñanza de lenguas extranjeras}

Calderón, Sonia, «Dificultad de los verbos fraseológicos en inglés para hispanohablantes», Letras 39 (2006) 205-222.

Castro García, Damaris, «Spanish/English Bilingualism and Finiteness Acquisition», Letras 40 (2006) 141-173.

Chacón Araya, Xinia, «A Materials Design Model», Letras 31 (1999) 91103.

Chacón Araya, Xinia, «Student's First Approach to Reading Comprehension: Pre-Reading Strategies», Letras 32 (2000) 121-136. 
Chacón Araya, Xinia, «The English Reading Comprehension Class: InReading and Post-Reading strategies», Letras 34 (2002) 43-58.

Chacón Araya, Xinia, «Programa de inmersión del Español como segunda lengua para profesionales», Letras 36 (2004) 161-174.

Chavarría Fonseca, Rosa Isabel, «Stereotypes of Latin American Women Found in the Textbook of Spanish-as-a-Foreign-Language», Letras 27-28 (1992) 133-162.

Chavarría Fonseca, Rosa Isabel, «Improving the Curriculum Through a Unified Content-Area-Based Approach», Letras 29-30 (1993) 173-200.

Chavarría Fonseca, Rosa Isabel, «English Locative Prepositions in, on, at and Spanish Locative Prepositions en and sobre», Letras 34 (2002) 59-72.

Eliason, Walter, «La adquisición de una segunda lengua como agente de cambio en la enseñanza», Letras 29-30 (1993) 153-171.

Hernández Villalobos, Jorge, «The Socio-Cultural Content of Textbooks and the Teaching of Culture in Foreign Language Programs», Letras 23-24 (1990) 83-104.

Jiménez Arias, Ivannia, «Writing is not so tough!», Letras 27-28 (1992) 163-191.

Jiménez Arias, Ivannia, «Treating Students' Errors in Oral Production», Letras 36 (2004) 175-188.

Núñez Quesada, María Gabriela, «Proyecto Francés y Educación: veinte años de esfuerzos por el mejoramiento de la enseñanza del francés en Costa Rica», Letras 40 (2006) 175-208.

Quesada Pacheco, Jorge, «Code Switching between Inglés y Español», Letras 23-24 (1990) 67-82. 
Rojas Campos, Oscar, «Authenticity in Listening and Written Texts», Letras 25-26 (1991) 169-194.

Rojas Campos, Oscar, «Procedimiento para analizar libros de texto comunicativos en la enseñanza de una segunda lengua o una lengua extranjera», Letras 27-28 (1992) 105-131.

Saborío Pérez, Ileana, «An ESL/EFL Computer Assisted Language Instruction (CALIS) Lesson on Coherence Through Sentences When Writing Compositions in the Foreign Language Classroom», Letras 36 (2004) 141-159.

Saborío Pérez, Ileana, «Introspección curricular de la enseñanza del Inglés desde primaria y secundaria y sus posibles repercusiones académicas», Letras 39 (2006) 273-278.

Tomcsányi Major, Judit, «Periodicidad y ciclicidad en la adquisición de los medios de expresión temporal en el inglés como lengua extranjera», Letras 36 (2004) 189-203.

Vega Carballo, Virginia, «Fonética y enseñanza del francés», Letras 25-26 (1991) 209-219.

Villalobos Rodríguez, Lelia, «A Comparison of the Psychological Processes in Top-Down and Bottom-Up Processing of Information in Schema Theory», Letras 25-26 (1991) 195-208.

Villalobos Rodríguez, Lelia, «Foreign Language in the Elementary School (FLES) A Curriculum Proposal for First Grades», Letras 29-30 (1993) 201 224.

\section{Literatura costarricense}

Acuña, María Eugenia, «La imagen de la mujer en la literatura costarricense de principios de siglo», Letras 23-24 (1990) 149-159. 
Araya, Seidy, «Frida Calho y Eunice Odio. El surrealismo latinoamericano, imágenes pictóricas y verbales», Letras 35 (2003) 103-115.

Araya, Seidy, «El advenimiento de una nueva realidad en Mujeres, sombras y coloquios de uno, de Eduardo Vargas Ugalde», Letras 38 (2005) 91-100.

Baltodano Román, Gabriel, «Los hilos de lo desconocido: Luzbel, de Gonzalo Arias Páez», Letras 38 (2005) 101-121.

Blanco Benavides, Carlos, «La sanción a un gamonal: "La propia", de Magón», Letras 35 (2003) 133-151.

Bolaños, Luis, «Un poeta entre la vocación y el deber: Entrevista con Carlos Francisco Monge», Letras 23-24 (1990) 213-230.

Budd, Ruth, «Basura y tesoros en el relleno sanitario de Río Azul: una nueva mirada a la "Suiza de América Central"», Letras 31 (1999) 121-130.

Calderón, Mínor, «Única mirando al mar: entre la transgresión y la norma», Letras 35 (2003) 173-184.

Cantillano, Odilie, «Los cuentos de tío Conejo», Letras 34 (2002) 5-42.

Carrasco, Candide, «Voces gay en la narrativa costarricense», Letras 35 (2003) 81-101.

Chacón Gutiérrez, Albino, «La inscripción de las mediaciones institucionales en Lázaro de Betania, de Roberto Brenes Mesén y "Caballo de trote", de Quince Duncan», Letras 35 (2003) 197-209.

Chacón Gutiérrez, Albino, «La literatura histórica en Costa Rica hoy», Letras 39 (2006) 227-235.

Chaverri, Amalia, «Cruz de olvido: historia, ficción y catarsis», Letras 35 (2003) 37-54. 
Chaves Alfaro, Iris, «Desconciertos en un jardín tropical de Magda Zavala: crónica de la posmodernidad», Letras 35 (2003) 153-172.

Cortés, María Lourdes, «El espejo, el andrógino y la madre», Letras 35 (2003) 55-64.

Enríquez, María, «Miradas convergentes sobre la cuidad en Los Peor de Fernando Contreras», Letras 37 (2005) 53-64.

González Duarte, Delma, «Signos de violencia en La colina de Daniel Gallegos», Letras 27-28 (1992) 25-47.

Monge, Carlos Franscisco, «El estante vacío (Reflexiones sobre la poesía contemporánea)», Letras 33 (2001) 5-20.

Monge, Carlos Franscisco, «Andanzas españolas de la poesía costarricense», Letras 40 (2006) 75-91.

Montanaro, Óscar, «Huellas de ceniza: primera novela policial de la literatura costarricense», Letras 35 (2003) 211-225.

Ovares Ramírez, Flora, «Tenía por sobrenombre Quesada», Letras 35 (2003) 7-10.

Ovares Ramírez, Flora, «La crítica en las revistas literarias en Costa Rica», Letras 39 (2006) 245-249.

Pérez Miguel, Rafael, «La huida imposible: "Rota la ternura", Marín Cañas», Letras 32 (2000) 5-18.

Pérez Miguel, Rafael, "Así nacimos (épica y antiépica en la literatura costarricense)», Letras 35 (2003) 227-235.

Quesada Soto, Alvaro, «La narrativa costarricense del último tercio de siglo», Letras 32 (2000) 17-44. 
Ramírez, Grethel, «Apuntes acerca de la ironía y otras variantes humorísticas», Letras 40 (2006) 9-31.

Robb, Anthony, «Uvieta: aproximaciones literarias», Letras 35 (2003) 25-35.

Robb, Anthony, «El ser sexual en la poesía de Eunice Odio», Letras 39 (2006) 107-140.

Rojas González, Margarita, «Nación y familia: En una silla de ruedas de Carmen Lyra», Letras 23-24 (1990) 161-185.

Rojas González, Margarita, «Escritura e identidad enel cuento costarricense contemporáneo», Letras 35 (2003) 185-195.

Salas Zamora, Edwin, «Génesis de la identidad costarricense en Asalto al paraíso», Letras 35 (2003) 117-131.

Singer, Deborah, «La construcción de la identidad nacional patriarcal en Misterio, de Manuel Argüello Mora», Letras 39 (2006) 87-105.

Valencia, Jhon, «Género, homofobia interiorizada y falocentrismo a través de La mujer oculta», Letras 35 (2003) 65-79.

Villalobos, Carlos, «La episteme dialógica: el camino teórico de Álvaro Quesada», Letras 35 (2003) 11-23.

\section{Literatura en lengua francesa}

Aguilar Gutiérrez, Alma Rosa, «Crear vínculos, mirar con el corazón», Letras 32 (2000) 171-180.

Aguilar Gutiérrez, Alma Rosa, «Heroínas naturalistas de la modernidad: Germinal de Emile Zola», Letras 37 (2005) 95-113. 
Dormond, Cinthia, «George Sand precursora del movimiento feminista», Letras 23-24 (1990) 137-147.

Haffner, Françoise, «Valéry mythoclaste», Letras 34 (2002) 87-104.

Retana Calderón, Róger, «Dixiéme Lettre: Sur le commerce, Lettres Philosophiques, Voltaire. Approache discursive», Letras 32 (2000) 163-170.

\section{Literatura en lengua inglesa}

Álvarez Martínez, Luis Gustavo, «Wrath in Diane Wakoski's Poetry», Letras 36 (2004) 205-213.

Álvarez Martínez, Luis Gustavo, «An Annotated Bibliography on the Rabbit Novels by John Updike», Letras 39 (2006) 161-182.

Barboza Núñez, Esteban, «The Uncanny in the Themes of Evil, Transgression, and the Double in Nathaniel Hawthorne's "Rappaccini's Daughter"», Letras 40 (2006) 33-47.

Durán Luzio, Juan, «"Crónicas marcianas": de la conquista de América a la conquista de Marte», Letras 25-26 (1991) 83-106.

Méndez, Carlos Adolfo, «El gran Gatsby de F. S. Fitzgerald: un acercamiento a su intertextualidad», Letras 27-28 (1992) 87-104.

\section{Literatura en otras lenguas}

Boza Araya, Virginia, «L'universe fantastique de Jean Ray», Letras 38 (2005) 123-151.

Calderón, Juan Roberto, «Entre dos sellos: el esoterismo islámico de la "Azora en los infieles"», Letras 37 (2005) 115-127. 
Calderón, Juan Roberto, «En el vientre de la redoma: los genios en Las mil y una noches», Letras 38 (2005) 153-165.

Calderón, Juan Roberto, «Breve acercamiento a la literatura árabe», Letras 31 (1999) 131-152.

Sánchez, Cristián Marcelo, «Entre dos sellos: el esoterismo islámico de la "Azora en los infieles"», Letras 37 (2005) 115-127.

Sánchez, Cristián Marcelo, «En el vientre de la redoma: los genios en Las mil y una noches», Letras 38 (2005) 153-165.

\section{Literatura española}

Alvarado, María Luisa, «El poema "Pisada humana" de Vicente Aleixandre», Letras 23-24 (1990) 201-211.

Baltodano Román, Gabriel, «Versos y reversos: a propósito de la voluntad, la lectura y El Quijote», Letras 39 (2006) 27-46.

Guzmán Arguedas, María de la Luz, «Juventud y vejez de Lope de Vega en su poesía», Letras 25-26 (1991) 5-24.

Ramírez Caro, Jorge, «El Lazarillo de Tormes: texto carnavalesco. Contra las lecturas satíricas y erasmistas», Letras 39 (2006) 47-71.

Ramírez Caro, Jorge, «Juego a escondidas entre Dios y el ser humano en la poesía de Antonio Machado», Letras 40 (2006) 49-73.

Wilson, Diana de Armas, «Cervantes y "La materia de america"», Letras 2930 (1993) 21-38. 


\section{Literatura hispanoamericana}

Aguilar Gutiérrez, Alma Rosa, «Sur l'universe fantastique de Julio Cortázar: analyse semantique de la referenciation dans Pasajes», Letras 31 (1999) 25-45.

Aguilar Gutiérrez, Alma Rosa, «Juegos referenciales y configuraciones espaciales el universo fantástico en "Ahí pero dónde, cómo" de Julio Cortázar», Letras 38 (2005) 49-73.

Araya, Seidy, «El examen ético de la historia en Cenizas de Izalco de C. Alegría y D. J. Flakoll», Letras 25-26 (1991) 61-82.

Araya, Seidy, «La mujer y la agresión en "Quince barrotes de izquierda a derecha" de Rosario Aguilar», Letras 29-30 (1993) 113-126.

Araya, Seidy, «El diálogo intertextual en Mayapán», Letras 32 (2000) 65-90.

Arrieta Vargas, Vilma, «Presencia satánica en el Río Danubio: anagramas en "Lejana", de Julio Cortázar», Letras 32 (2000) 45-64.

Arrieta Vargas, Vilma, «El eco de otra Alina, Intertextualidades en "Lejana" de Julio Cortázar», Letras 38 (2005) 75-89.

Azofeifa, Isaac Felipe, «Notas para una interpretación provisional de la poesía en Latinoamérica», Letras 23-24 (1990) 187-199.

Barzuna Pérez, Guillermo, «Del contexto y los desplazamientos en la nueva canción latinoamericana», Letras 27-28 (1992) 7-23.

Castro Villalobos, Marielos, «Lectura sociohistórica y simbólica de El luto humano de José Revueltas», Letras 27-28 (1992) 69-86.

Chaves Alfaro, Iris, «"Las babas del diablo" de Julio Cortázar: la rebelión del relato», Letras 27-28 (1992) 49-66. 
Durán Luzio, Juan, «Borges y los libros», Letras 31 (1999) 153-156.

Gamboa Goldemberg, Jaime, «Borges y Dios en el jardín del soneto», Letras 25-26 (1991) 25-40.

Gamboa Goldemberg, Jaime, «Lectura y consagración en El hondero entusiasta de Pablo Neruda», Letras 33 (2001) 143-150.

Gómez, Gilberto, «El proyecto nacional colombiano y la defensa de la aristocracia en Pax y El alférez real», Letras 37 (2005) 65-77.

Lavou Zoungo, Victorien, «Indigenismo y marginación de los negros en América Latina», Letras 33 (2001) 129-142.

Limami, Abdellatif, «La cuidad marroquí en Los nombres del aire de Alberto Ruy Sánchez y Aguafuertes españoles de Roberto Arlt», Letras 34 (2002) 105-120.

Maristany, José María, «El vuelo del tigre: una contestación doblemente marginal», Letras 29-30 (1993) 55-73.

Matarrita, Estebana, «La relevancia de la excusa en El negro Francisco», Letras 34 (2002) 155-168.

Ovares Ramírez, Flora, «Espacios de tránsito en los cuentos fantásticos de Julio Cortázar», Letras 31 (1999) 5-24.

Quesada Monge, Rodrigo, «El problema del antiimperialismo en Máximo Soto Hall», Letras 25-26 (1991) 41-59.

Ramírez Caro, Jorge, «Un laberinto para jugar a la soledad: "La casa de Asterión"», Letras 38 (2005) 27-48.

Rojas González, Margarita, «Espacios de tránsito en los cuentos fantásticos de Julio Cortázar», Letras 31 (1999) 5-24. 
Rojas González, Margarita, «El libro maligno: Aura e Inez», Letras 38 (2005) 9-26.

Rojas González, Manuel, «Música callada: literatura y arte musical en tres cuentos hispanoamericanos», Letras 37 (2005) 79-94.

Shmigalle, Günther, «Escándalos de París. Rubén Darío y Gyp frente al asunto Syventon», Letras 37 (2005) 31-51.

Sirias, Silvio, «El nuevo "boom": la novela hispanoamericana en los Estados Unidos», Letras 29-30 (1993) 39-53.

Thornton, Sally, «Highlighting Ambiguities: the Fictionalization of a Woman's life in Lorenza Reynafé o Quiroga, la barranca de la tragedia», Letras 33 (2001) 21-32.

Torres-Pou, Joan, «La carnavalización del discurso naturalista en $A$ fuego lento, de Emilio Bobadilla», Letras 39 (2006) 73-86.

Umaña, José Otilio, «Interpretación y traducción de América en el "Diario de Navegación" de Cristobal Colon», Letras 25-26 (1991) 107-119.

Umaña, José Otilio, «Peregrinaciones hacia lo grotesco: tres cuentos de García Márquez», Letras 29-30 (1993) 101-112.

Valembois, Victor, «Cien años de soledad: realismo belga en lo maravilloso», Letras 31 (1999) 105-120.

Valembois, Victor, «Miguel Ángel Asturias y Bélgica: curiosas pistas reales e imaginarias», Letras 32 (2000) 107-120.

Valembois, Victor, «De Bartolomé de Las Casas al TLC, pasando por Multatuli», Letras 39 (2006) 141-159.

Vidaurre, Carmen, «Acercamiento analítico a Perésfone de Homero Aridjis», Letras 33 (2001) 151-159. 
Villaceque, Sol, «Ruptura y modernidad. La renovación de los estereotipos en la Argentina de los años 20: El juguete rabioso de Roberto Arlt», Letras 34 (2002) 121-154.

\section{Semiótica}

Barzuna Pérez, Guillermo, «Graffiti: la voz ante el silencio», Letras 37 (2005) 129-138.

Gaínza, Gastón, «La lectura de la otredad», Letras 29-30 (1993) 7-20.

Gaínza, Gastón, «Pespuntes semióticos», Letras 31 (1999) 47-68.

Gaínza, Gastón, «El libroy la provocación del sentido», Letras 39(2006) 11-25.

Grivel, Charles, «Buñuel ou l'insoutenable filmique», Letras 29-30 (1993) 127-152.

Guzmán Arguedas, María de la Luz, «El análisis retórico de la publicidad», Letras 23-24 (1990) 127-136.

Yglesias, María Pérez, «La ironía del chiste», Letras 34 (2002) 185-199.

\section{Teoría literaria y estética}

Carcaud, Monique, «Sociocrítica y fenómenos de transtextualidad», Letras 33 (2001) 101-114.

Ramírez Caro, Jorge, «Lecturas intertextual e interdiscursiva en Sociocrítica», Letras 32 (2000) 137-162.

Rojas González, Margarita, «Los estudios teóricos de la literatura y la necesidad de la interpretación», Letras 39 (2006) 251-65. 
Soriano, Michelle, «Esfinges y panteras: diferencia e ideología. Hacia un análisis sociocrítico de la apuesta especular», Letras 33 (2001) 115-128.

Urra Salazar, Marcos, «Reflexiones teóricas acerca del cuento», Letras 2324 (1990) 105-126.

\section{Traducción e interpretación}

Benavides Segura, Bianchinetta, «El tratamiento completo: alternativa para la traducción del verso inserto en prosa no literaria», Letras 39 (2006) 183-203.

Benavides Segura, Bianchinetta, «La traducción de verso inserto en prosa: dos casos», Letras 40 (2006) 93-115.

Dianda, Ana María, «Intertextualidad y simbolismo: su importancia en la traducción y la recreación del texto literario», Letras 32 (2000) 91-106.

Gaínza, Gastón, «La traducción: interacción de semiosferas», Letras 39 (2006) 237-244.

Gapper, Sherry, «Anexo a "La teoría y el arte de la traducción" de Peter Newmark: Bibliografía esencial sobre traducción», Letras 23-24 (1990) 59-66.

Gapper, Sherry, «La traducción como campo de estudio: tendencias y posibilidades actuales», Letras 25-26 (1991) 121-138.

Gapper, Sherry, «La firma de quien traduce», Letras 36 (2004) 81-99.

Gólcher, Ingrid, «Educación del traductor como pensador crítico», Letras 36 (2004) 65-80.

Kühlmann Berenzon, Helga, «La formación del traductor en el lugar del trabajo», Letras 36 (2004) 119-139. 
Newmark, Peter, «La teoría y el arte de la traducción», Letras 23-24 (1990) 27-58.

Novo Díaz, Margarita, «La evaluación de las actividades de interpretación», Letras 36 (2004) 9-25.

Pineda Rodríguez, Allan, «La traducción de criptogramas y poemas en $\mathrm{El}$ Código Da Vinci», Letras 40 (2006) 117-140.

Rodríguez, Cristián, «Traducciones comerciales y traducciones literarias», Letras 36 (2004) 219-224.

Rojas Campos, Oscar, «El portafolio y la evaluación del proceso en traducción», Letras 36 (2004) 27-64.

Sánchez García, Manuel, «Algunos problemas en la traducción al español del soneto XX de William Shakespeare», Letras 27-28 (1992) 217-231. 

Esta revista se imprimió en el mes de marzo del 2007 en el Programa de Publicaciones e Impresiones de la Universidad Nacional, bajo la dirección de Maximiliano García Villalobos, consta de un tiraje de 500 ejemplares, en papel bond y cartulina barnizable. E-30-6--P.UNA 



\section{Revista Letras \\ Normas editoriales para la presentación de artículos}

1. Letras admite estudios de alto valor académico sobre lingüística, literatura, enseñanza de segundas lenguas, semiótica, traducción, y materiales de importancia documental para las disciplinas que competen a la Escuela de Literatura y Ciencias del Lenguaje.

$\therefore \quad$ Los artículos deben ser estrictamente originales, inéditos y no estar aprobados para su publicación en otro lugàr. El autor, además de ser enteramente responsable de los contenidos, deberá respetar y atenerse al rigor y a la ética propios de la actividad académica nacional e internacional.

1. En todos los casos, en los artículos se deberán respetar las normas internacionales de propiedad intelectual en las citas y reproducciones de materiales.

-1 La dirección y el comité editorial son los responsables de la selección y evaluación de los artículos, y procurarán que cada número guarde coherencia y uniformidad en sus contenidos particulares, aunque no será criterio fundamental para la publicación o selección del material. Cuando se considere oportuno, se publicarán números especiales o secciones sobre algún asunto particular de interés académico.

i Los artículos deben tener una extensión de 20 a 30 folios (tamaño carta: $21,5 \mathrm{~cm}$. x $28 \mathrm{~cm}$.), a doble espacio, a razón de 26 líneas por página (es decir, entre 4500 y 7500 palabras). Si está escrito por dos autores, se admite una extensión máxima de 40 folios (10.000 palabras). Deberán presentarse en versión impresa (tres ejemplares) y en formato digital (transcritos preferiblemente en versiones recientes de Microsoft Word ${ }^{3}$ ). Cada autor deberá aportar, además, la información personal pertinente (institución, dirección electrónica y postal, número telefónico, etc.).

(1 El artículo puede estar escrito en español, en inglés o en francés, y su redacción será la definitiva. Debe estar precedido por un resumen en español, de un máximo de 100 palabras, y su versión a otro idioma moderno de uso internacional (preferiblemente el inglés); además, se deben agregar las palabras clave (keywords) para facilitar la indización del artículo.

l Para las citas bibliográficas y notas se recomienda seguir las más habituales normas estilísticas aceptadas internacionalmente. Se recomiendan las directrices del manual de la MLA (con las adaptaciones al español, cuando corresponda, según el uso fijado en números anteriores de la revista LETRAS). Las transliteraciones de alfabetos no latinos se atendrán al uso apropiado y a la normativa establecida internacionalmente.

k. Los aspectos estilísticos referidos a la tipografía y otras normas de impresión, así como otros aspectos gráficos, quedan a cargo de la dirección de LETRAS. 